\title{
Students with Varied Degrees of Asianness: Goldmine for Crosscultural Exchange
}

\author{
Etsuko Toyoda \\ The University of Melbourne, Australia
}

\begin{abstract}
In many Australian universities, "Asian” students have become a prominent feature in Japanese language courses. Some experts in Japanese language education express concern that this popularity amongst Asian students may shake the perception of Japanese as a subject in which students from all backgrounds can compete fairly, and that this phenomena may be a disincentive for non-Asian students to learn the language. I argue that we should not dichotomize students into Asian and nonAsian, since the degree of Asianness in Asian students in fact varies greatly. We should make the most of what we have; students with varied backgrounds are a goldmine for crosscultural exchange. In this paper, I firstly examine students with different degrees of Asianness, and analyzes their motivations for learning the language, and their perceptions about the course. The study reveals that certain motivations and perceptions are affected by the degree of Asianness, but not as a binary mapping (Asian vs. non-Asian). Based on the findings, I make suggestions for turning the classroom environment into one more conducive to crosscultural learning, and thus beneficial to all students. Lastly, I present a pilot study built around the suggestions.
\end{abstract}

\section{Introduction}

In 2012, the Australian government released a white paper entitled "Australia in the Asian Century", which proposes an increased engagement with Asian countries. This white paper places great emphasis on the learning of Asian languages. In contrast to the government's aspiration to increase the number of Australians fluent in an Asian language [6], there had been a decrease in the number of students learning the Japanese language [9]. Despite the decrease, statistically, Japanese still remains the most widely studied language in Australia at present [8]. However, the demographic change in learners is evident. This is partly due to a marked rise in the number of "Asian" students. In Australia, "Asian students" refers to students who have an ethnic background in South-Eastern Asia. A large proportion of Japanese language learners in Australia is of Asian-background, including many Asian international students [11]. Japanese language learning has recently become particularly popular amongst students of a Chinese or Korean background [9]. It is believed that this popularity among Chineseor Korean-background students is due to the similarity of their language to Japanese. Chinese and Japanese partially share a common script. One type of script used in Japanese originated in China. These Chinese-originated Japanese characters often have similar, if not the same, physical shapes to Chinese characters. Korean and Japanese have similar syntactic structures.

Some experts are concerned about this popularity amongst Asian students [8]. In Japanese courses in Australian schools/universities, the number of local students with a home background in Japanese is relatively small, unlike the case of Chinese courses. For this reason, Japanese courses were regarded as a 'normal foreign language learning' environment where students from a range of backgrounds could study [8]. However, this perception has been undermined due to the recent surge of Asianbackground learners. It is widely believed that Asian students have advantages in studying Japanese because they are already familiar with Asian language(s) and culture(s), and that non-Asian students are demoralized by the thought that they have to compete with them [12].

It is undoubtedly important to provide an environment where Australians of all backgrounds (particularly those from a monolingual family) feel that they can study and compete fairly. However, it should not involve demonizing Asian students. An article in the Sydney Morning Herald [19] proposed, after pointing out conspicuous presence of Asian students, "Instead of spending money on expensive schemes to expand the teaching of Asian languages in Australia, we spend the money on sending young Australians to live in Asia and learn a language there." Proposals such as the above derive from the misconception that students can be classified dichotomously, i.e. Asian versus non-Asian, or international versus local.

There are numerous research papers reporting the differences between Asian international students and local students (e.g., [13] and [17]). In such 
comparisons, authors intentionally or unintentionally draw a picture of two types of students: newcomers with Eastern culture and domestic students with Western culture. However, it is potentially hazardous for research to classify students dichotomously, Asian-background and non-Asian-background. In fact, the degree of Asianness in Asian-background students varies greatly: from those who received most of their education in an Asian country and have come to Australia as international students to those who are ethnically Asian but have little Asian language and culture and identify themselves as culturally Australian. In fact, the latter differ little from non-Asian students.

We should not dichotomize and classify students into two categories, Asian and non-Asian, since 'Asian students' are not one group with the same amount of exposure to Asian languages and cultures, just as 'local students' are not a homogeneous group. The diversity of students in Asian language classes can be turned into an ideal environment for crosscultural learning.

The aims of this study are 1) to examine students with different degrees of Asianness (from non-Asian students to native speakers of an Asian language) and investigate their motivations for learning the target language and their perceptions about the course; 2) to make pedagogical suggestions for turning the classroom into a more desirable environment for intercultural learning, beneficial to all students; and 3) to present a pilot course built around the suggestions.

\section{Different degrees of Asianness}

\subsection{Motivation and perception study}

This section reports a study investigating, for students with different degrees of Asianness, their reasons for taking a Japanese language subject, and their perceptions of the course. An online survey was used to collect data. The first half of the survey consisted of questions to gather background information, and history of, and proficiency in, any languages learnt. The second half of the survey had two sections: the first section consisted of questions asking the reasons for studying the particular subject (motivation data), and the second section consisted of questions to investigate perceptions about the course (perception data). Participants in this study were students enrolled in Japanese courses at an Australian university. Students had different degrees of Asianness, from non-Asian students to native speakers of an Asian language.

For motivations, possible reasons, originally obtained from an informal interview with former students, were provided from which students could choose. Students were asked to tick as many reason(s) for studying the language (e.g., It is useful for traveling). For perceptions, adjectives representing either positive or negative feelings were listed together with a scale of 1-5. Students were asked to indicate how strongly they identified with an attribute represented by each adjective. At the bottom of the survey, a free text box was provided for comments, and students were encouraged to express their feelings and opinions. They were allowed to take as much time as necessary. Students' responses were automatically recorded.

For both the motivation and perception data, crosstab analyses were conducted, and Goodman and Kruskal's gamma was used in order to test the strength of association of the cross tabulated data, precisely, between the degree of Asianness and each of the reasons and feelings. For the reasons for studying, factor analysis was performed to identify affecting attributes, with which the degree of Asianness correlated. Significance level was set to be 0.05 .

\subsection{Survey results and discussion}

In order to test the strength of association between the degree of Asianness and each of the reasons and feelings, firstly students' Asianness was examined. According to the degree of Asianness indicated in the background information obtained from the survey, the students were categorized as strongly Asian, moderately Asian or least Asian. Strongly Asian students (SA) were born and raised in an Asian country, and their first language was one of the Asian languages. Moderately Asian students (MA) were those who had most of their education in Australia, and they were bilingual in English and an Asian language, both at a native or near-native level. Least Asian (LA) were all educated in Australia. They were monolingual or with a low level Asian language ability. Out of a total of 330 students, 139 $(42 \%)$ were classified as SA, $96(29 \%)$ as MA, and $95(29 \%)$ as LA.

The reasons with which the majority of students across the board agreed were: 1) I like the traditional culture, 2) It is useful when traveling, 3) I like the sound of the language, 4) I like the pop culture, 5) I have studied the language before.

Some reasons were found to correlate with the degree of Asianness. The students who had a higher degree of Asianness tended to study the subject because: "It shares a common script with my language" $(\gamma=.639)$; "the structure is similar to that of my language" $(\gamma=.613)$; "I don't feel inferior in terms of the language use - no English barrier problem" $(\gamma=.471)$; "I can be with other students from my own country/culture" $(\gamma=.471)$; "I feel comfortable in a class with many Asian students"; $(\gamma=.341)$ and "the relationship with teachers is comfortable' $(\gamma=.226)$. Students identified as being less Asian tended to take Japanese because: "I have 
studied it before" $(\gamma=-.389)$ and "I like the pop culture" $(\gamma=-.193)$.

The above reasons, where correlations with Asianness were found, were then put through factor analysis. The following factors were identified as attributes differentiating the students in terms of degree of Asianness. A "+" sign shows that the factor is positively correlated to the Asianness and a "-" denotes that the factor is negatively correlated.

+ Comfortable class environment (no English barrier, many Asians, people from one's own country, and good relationship with teachers)

+ Linguistic similarity (similar structure and script)

- Cultural attraction (pop culture)

- Prior investment (experience of studying)

With regard to perceptions about their Japanese course, the students with a stronger degree of Asianness had more positive feelings than did the students with a lesser degree of Asianness. As the degree of Asianness increased, the more positive the feelings expressed, as indicated by the following adjectives: Happy $(\gamma=.327)$; comfortable $(\gamma=.349)$; familiar $(\gamma=.278)$; at home $(\gamma=.170)$; involved $(\gamma=.256) ; \quad$ relaxed $\quad(\gamma=.221)$; suited $\quad(\gamma=.263)$; confident $(\gamma=.338)$. Negative feelings were more evident in the students with a lesser degree of Asianness: Stressed $(\gamma=-.218)$ and isolated $(\gamma=-.145)$.

\subsection{Discussion}

In this section, the above results are discussed in a wider context by incorporating the findings from previous studies.

The SA group consisted of international students from an Asian country, or local students who had been in Australia for only a few years. They were all multilingual, with stronger skills in an Asian language than English (for the majority), or were balanced bilingual/trilingual in Asian language(s) and English. The majority of SA participants (about $80 \%$ ) were educated in a Chinese-speaking country, and spoke a form of Chinese as the first language. A significantly large number of SA selected "linguistic similarity" (similar/same structure and script) as a reason for studying. While it is true that Chinese partially shares script with Japanese, the sentence structures of Chinese and Japanese are in fact distinct. The number of Korean-background students who were likely to find similarity in the structures was minimal (only 3\%) in this SA group. The result indicating that many students chose "similar structure" was an interesting surprise.

For the students with Chinese-background, learning Chinese-originated Japanese characters is less intimidating than it is for those with nonChinese-background. This is undeniable. However, concluding that "Asian" students are advantaged in learning Japanese is not necessarily the whole story.
Firstly, not all SA were Chinese language literate. About one fifth of SA were unfamiliar with the nonphonological script (i.e., Chinese-originated Japanese characters). Secondly, SA had other reasons for taking Japanese language subjects, such as "liking traditional/popular culture" and "the usefulness the language for work and travel". Some viewed the course as an opportunity to pursue their interests and/or to further their careers. Lastly, the SA might have felt it necessary to take an Asian language subject in order to alleviate the stress of competition in other courses, with English native speakers who likely have an advantage in manipulation of the English language and in execution of some classroom activities, such as discussions and presentations.

This last point may be a crucial aspect. Many studies on international students point out that newcomers experience stress, anxiety, lack of confidence, low self-esteem, demotivation, and withdrawal (e.g., [4], [5] and [15]), all of which are symptomatic of acculturation problems. Acculturation is defined as "a process that individuals undergo (usually later in life) in response to a changing cultural context" [2]. In this process, newcomers face acculturation problems resulting from intercultural contact that cannot be dealt with easily or quickly by simply adjusting or assimilating to the new culture [3].

Partly to escape from this plight, some SA might have chosen to take a Japanese language subject, in which they could feel less stressed. Indeed, the reasons relating to "comfortable class environment" were selected by this group of students significantly more than by the other groups. The results from the perception section of the survey supported this. SA viewed their courses significantly more positively than do the other groups.

The MA group consisted of Asian-background local students (Australian nationals, mostly by birth, but with a few having obtained citizenship later in life) who had been mostly educated in Australia. These students were all bilingual/multilingual in English and Asian language(s). For both motivations and perceptions, the results placed the MA group between the SA and the LA.

Approximately half of the MA students (55\%) had some knowledge of the Chinese language. These students might have had some advantages in learning Japanese due to the visual similarity between Chinese characters and the characters used in Japanese. Students who had a command of Korean were few $(6 \%)$, but they might also have had some advantage since the Korean language has a syntactical structure similar to that of Japanese. These potential advantages might be part of the reason for enrolling in the course. This is supported by the results of a non-statistical comparison between the Chinese background (53 students), 
Korean background (6 students) and other nonChinese/non-Korean Asian students (37 students). The Chinese background students tended to select "similar script" as a reason more than did other student categories. Likewise, the Korean background students tended to select "similar structure" more than did other categories. The students in the nonChinese/non-Korean Asian students tended to favor "cultural attraction (pop culture)". "Comfortable class environment" attracted the Korean and nonChinese/non-Korean Asian students, but not the Chinese students.

These three categories of Asian-background students were spread across the course levels. The Japanese courses have a mixture of MA students with different backgrounds and different motivations.

The students in the LA group were all Australianeducated local students with little ability in an Asian language. Like SA and MA, LA also selected "I like the traditional culture" as one of the top reasons for studying Japanese. "I like the pop culture" was also one of the top reasons. This was more significant in the LA group than the other groups. This indicates that Japanese pop culture such as anime films may be a driving force for studying the language for those who have little connection with Asia. The popularity of Japanese pop culture and its application to Japanese language instruction have been well discussed recently (e.g., [1] and [18]). Thomson [18] recommends the incorporation of pop culture into the curriculum, since, according to her survey, many students are interested in Japanese pop culture. However, although emphasis on pop culture may suit LA, the current survey shows traditional culture is more attractive than pop culture to students in general.

The majority of LA students seem to study the language because they think it may be useful when they travel to a country where the language is spoken. Since the Japanese language is not a necessity for living in Australia, this is an expected response.

The proportion of LA selecting "I have studied the language before" was significantly higher than SA and MA groups. This may be explained as follows. There are many students with good Chinese knowledge in Japanese courses. Whereas Chinesespeaking students in Chinese language courses would be placed in an advanced course, these students in Japanese language courses are most likely to be treated as beginner students if they have no prior experience of Japanese. At the same time, these students with Chinese linguistic knowledge would certainly have an advantage in learning Japanese script because of the visual familiarity. There are a few Korean background students, and they would have an advantage in understanding the syntax of the language, as it is similar to their own. It is plausible that the non-Chinese and non-Korean background students in the current study felt it necessary to have some prior knowledge of Japanese in order to compete with the background students.

Noteworthy comments often come from nonAsian students expressing negative feelings towards their courses, such as feeling stressed, threatened, isolated and depressed in having to compete with Asian classmates and receiving little support from teachers. The results of the current study supported this. The LA students perceived their classes more negatively than the other groups. There appeared to be a strong belief among the students that "Asian" students could read and write Chinese characters, and therefore it would be easy for them to learn Japanese. This reflects the stereotypical view shared by the wider community.

As examined and discussed above, "Asian" students are not one group of students who have the same amount of exposure to Asian languages and cultures. In fact, they are diverse in experience and competence, but happen to have a similar appearance. It is worth pointing out that not only non-Asian students, but also ethnically Asian students who were brought up without much exposure to an Asian language and culture, can be negatively affected by this belief. It poses an unnecessary threat to the former and unjustified prejudice towards the latter.

\section{Pedagogical suggestions}

Separating Asian students from non-Asian students, as suggested by some experts, is not a solution because Asians are not one group of students with the same attributes. Instead, I argue that an Asian language course can be transformed into an ideal intercultural learning environment while retaining a mix of student profiles.

To this end, I propose three changes. The first concern in the current situation is that students who have little or no contact with Asia are experiencing psychological stress (similar to the acculturation stress international students would experience). That is, these students are experiencing quasi study abroad, as the situation is analogous to the acculturation stress international students would experience (For international students' stress, see [4], [14] and [15]). Experts in the education sector, students and parents need to be aware of the positive aspects of experiencing acculturation stress (culture shock). Wherever people from different cultures gather, there is tension to some extent, and people in a minority group experience some degree of stress. In this global age, young people need to be prepared for such situations.

At the same time, it is also important that unnecessary stress be removed. As discussed, not all Asian students have an advantage in learning the Japanese language. In this study, $20 \%$ of SA, $39 \%$ of 
MA, and also the ethnically Asian students in the LA group did not have the potentially useful prior knowledge of characters. Students should be given an opportunity to learn about the diversity of Asian languages.

The second concern is that conventional language courses focus on four skills, speaking, listening, reading and writing, and in most case, accuracy is emphasized (i.e., included in assessment criteria). In such an environment, students with a Chinese background are likely to be more advantaged than those with a lesser degree of Asianness in reading and writing of the Japanese script. In order to equalize the workload amongst students, a heavier emphasis in assessment should be placed on research, communication (presentations, mini lectures, etc), and analysis skills [16], rather than on accuracy of language skills.

In relation to this issue, Matsumoto [10], which investigated the sustaining motivation of Asian and non-Asian background students learning Japanese, found that the attrition of Asian students was larger than that of non-Asian students. He interpreted that the familiarity with the Japanese language and culture made them underestimate their workload. Thus, Asian-background students who experience an easy ride at the start may be less likely to continue studying Japanese, compared to non-Asianbackgrounds who are smitten by cultural interest of Japan. By making a classroom more intercultural, students with a stronger degree of Asianness may focus on the cultural side of Japan and related countries, and students with a lesser degree of Asianness may not be demoralized by the laborious amount of work of studying script.

The third concern is that, in the classroom, students tend to sit with other students with the same background, and form cliques. Perhaps this is because international students who are fairly new to the country feel insecure in an unfamiliar environment and non-Asian students feel uncomfortable surrounded by a large number of Asian students.

This is not an ideal condition for crosscultural learning. The central goals of crosscultural learning are, as described in Gobel and Hlmke [7], cultural awareness, acceptance of cultural differences, and interest in the specific culture of the target language as well as in intercultural topics in general. Therefore, it is essential that students are given opportunities to talk to students with different backgrounds. It is necessary for students to feel that it is totally acceptable to express their opinions because there are various worldviews and there are no right or wrong views. In this regard, it is important for the instructor to foster students' appreciation of views expressed by others.

\section{Implementation}

This section describes one trial course where the above suggestions were implemented. The ultimate goal for this pilot course was to enhance students' literacy skills for conducting in-depth research related to the Japanese language and/or culture. The students enrolled in this course consisted of 17 strongly Asian, 11 moderately Asian and 13 least Asian students. The categorization of the degree of Asianness was made according to the criteria used for the motivation and perception study. However, a few strongly Asian students had lived in Australia for six or seven years, which made the border line between SA and MA a little obscure. They all possessed an intermediate level of Japanese at the start of the course.

The materials used were gathered from many sources, including novels, news articles, blogs, interview articles, and video clips, describing current issues in Japan emerging through globalization. The materials were used to give the students literacy and background knowledge and to build up vocabulary and expressions necessary for following-up discussions, presentations and essay writings. The students were encouraged to exchange opinions in class, and were also asked to conduct a small scale research project relating to the themes covered in the materials, and write an opinion piece and present it to the class.

The following aims were targeted in this course.

1. Alleviate potential stress of being a member of a minority group.

In this course, the students were spread across the spectrum of Asianness. However, the students who did not have Asian appearance were few, and they were apt to have felt stressed. In order to alleviate the potential stress, instead of focusing on accuracy of language use, application of literacy and background knowledge was emphasized. For example, discussion constituted a main activity, where the students were encouraged to express opinions without being stopped for correctness. Prior to a discussion, the students studied a reading material with a list of essential vocabulary and expressions as an aid. In the discussion, they were encouraged to apply both the contextual and linguistic knowledge that they acquired from reading, in order to express their opinions.

One of the assignments of the course was to give a mini lesson to the class, in which the students were asked to talk about what they thought they knew better than other classmates. For example, after learning about the excessive use of Japanglish (English-originated Japanese words that have drifted away from original meaning), one student talked about Singlish (English used in Singapore). Another student talked about the differences between British, American and Australian English. These activities were all conducted in Japanese. Both discussions and 
mini-lessons gave the students from all backgrounds opportunities to learn, not only from the teacher, but also from each other.

2. Balance study workload among students with an educational background in different script.

The learning of the Japanese script, particularly Chinese-originated characters, is laborious, which is even more so for non-Chinese-background students. While for Chinese-background students, learning this script is analogous to English speakers learning Spanish (i.e., learning words that often have the same or similar spellings with different. or occasionally similar, pronunciations), for non-Chinesebackground students, it is the learning of completely unfamiliar script. Within this trial course, in order to reduce the workload gap between the Chinese background and the non-Chinese background students, recognition, instead of reproduction was emphasized.

To this end, instead of script writing tests, multiple-choice recognition tests were administered. Conventionally, students have been required to be able to read (pronounce) and write Chineseoriginated characters correctly. However, in this era of technology, the writing of characters by hand is rare. Writing characters on the computer requires the ability to pronounce them (in order to type in the phonetics of the characters using a Roman alphabet keyboard) and to recognize the correct one out of a list of homophones. In this respect, asking students to become able to recognize a large number of the characters, rather than being able to write a limited number of characters, is justifiable. The exposure to a large number of characters and their pronunciations benefitted both the Chinese- and the non-Chinese background students.

3. Give opportunities to talk with other students from different backgrounds.

In Japanese classrooms, it is not uncommon to see international students clumping together in one corner, and non-Asian students in another corner, and local Asian-background students scattered around. In this course, in order to give them opportunities to communicate with people from a different background, at the time of discussion, the students were encouraged to move around and sit with those with whom they had not previously talked.

Also, for their research project, the students were required to form a mixed group of students with different backgrounds. At the beginning of the course, the students filled out a short background survey, and according to their background history, they were classified into one of the three Asianness categories. For the project, one of the criteria was forming a mixed group, and each member contributing from a different perspective towards the same topic.

At the end of 12 weeks of classes, the students were asked to evaluate their experience. Overall, the course was highly appreciated. With regard to the discussion, most students appreciated abundant opportunities for talking. Comments such as "I found the classes much more open in discussion with others than past classes which made it more enjoyable and less stressful" were heard. However, while many students "felt more comfortable and confident with their ability to use Japanese than before", some felt quite the opposite. One LA student commented that she felt intimidated by the large gap in ability by saying, "there are a few students who are really good, which raises the class standard by a lot and so sometimes I fall behind". This sort of intimidation might have caused to make some (shy) students feel less confident in their ability to talk.

It was expected that students with a stronger degree of Asianness would be shy and hesitate to speak up, as they had most of their schooling in an Asian country where passive-receptive style of learning is common [15]. By contrast, students with a lesser degree of Asianness were expected to contribute to the discussions more than those with stronger Asianness. It seems there is little association between the degree of participation and the students' background. Presumably, the students' speaking ability and personality affected their participation more than did their background. In order to make everyone comfortable, as pointed out by a student, "Much more work needs to be put into making sure that people aren't afraid of take risks and make mistakes, that everyone is comfortable around the other members of the class and that speaking in Japanese is no longer scary".

Generally Mini-lessons were highly appreciated, as can be seen in the comments such as "I enjoyed the mini-lesson. It was fun to learn from other students!!" and "I think it successfully gave us opportunities to learn about other cultures, and to reflect on our own". However, there were no comments suggesting that the discussions and minilessons helped in reducing stress caused by the perception of unfairness.

With regard to the learning of characters, the students with a lesser degree of Asianness welcomed the new move. Some LA students commented, such as, "Glad for the emphasis taken off kanji. Very relieved" and "I am very glad that stress of learning kanji has been relaxed a little". In terms of balancing study workload among students with an educational background in a different script, it seems it was successful. However, one MA student indicated that he "preferred to learn how to write kanji, not just read them". There were no comments from SA students in this regard.

In respect to the third point, i.e., giving opportunities to talk with other students from different backgrounds, there were mixed reactions. Examples of the positive reaction are: "I think the mix grouping for presentation is good cos we can 
have chance to cooperate with local students, not only our own friends" and "I liked the idea of mixing people up for group projects. I got to know people who I wouldn't normally get to know". The former comment was made by a SA student, and the latter came form a LA student. On the other hand, some MA students voiced otherwise. They thought that "it wasn't necessary to push for mixed groups for the projects, given that the groups would probably be pretty mixed anyway". One of them expressed that it was inefficient, as follows.

"I understand the idea behind wanting us to make groups with people from different backgrounds, but it's just easier and more efficient to make groups among friends."

The students with a moderate degree of Asianness did not see the value of forming a mixed group, probably because they already had friends from different backgrounds outside of the classroom with whom they could exchange opinions.

The trial course can be claimed to be successful in some respects although more rigorously structured studies are required. Much more interaction between students with different backgrounds was observed, compared to more conventional classrooms. Through the discussions, mini-lessons, and project work, some students claimed that they learnt not only about the Japanese language and culture, but also about other languages and cultures, and had an opportunity to reflect on their own language and culture. However, it has become clear that it is not easy to please all students, and that more efforts are required for the creation of intercultural learning environment from which students from different backgrounds can benefit.

\section{Conclusion}

The results of the survey have revealed that there is a strong association between the degree of Asianness and motivations and perceptions. Students with a stronger degree of Asianness have a stronger tendency to nominate "comfortable class environment" and "linguistic similarity" as reasons for taking Japanese subjects. Students with a lesser degree tend to nominate 'cultural attraction' more than do those with a stronger degree of Asianness. Students with stronger Asianness have more positive feelings about their courses than do those with lesser Asianness. Thus, the tendency is skewed by the degree of Asianness, but it is not a binary mapping (Asian vs. non-Asian). Students are spread across an entire spectrum of Asianness. Students from different backgrounds have different motivations and perceptions. This itself is benign. However, it does become an issue if the presence of students of a particular background creates an unfair advantage or unnecessary stress to those of different backgrounds.
It is crucial to create a course where students with varying degrees of Asianness can learn satisfactorily, without feeling disadvantaged or stressed. With small adjustments to alleviate the negative feelings, Asian language courses at a university may be turned into an ideal environment for crosscultural learning. Having different backgrounds means a treasure trove of different knowledge and experiences. A classroom should be a space for sharing this treasure.

The small-scale implementation of intercultural learning with students with a varied degree of Asianness has, at least partially, proved that an Asian language course could be an ideal intercultural learning environment while retaining a mix of student profiles. More studies are, however, needed in order to assess the merits and otherwise of the suggested approach.

In many Australian universities, a large number of Asian students has become a prominent feature in Japanese language courses. In response to this, experts in Japanese language education express concerns. They fear that this popularity amongst Asian students may negatively impact the perception of Japanese as a subject in which students from all backgrounds can compete fairly, and that this phenomenon may be a disincentive for non-Asian students to learn the language. The stereotypical preconception that non-Asian students are disadvantaged by Asian students has spread widely among educators, parents and students. This damaging perception of unfairness, not the reality, is the one that needs to be targeted. I believe that we, educators, should act proactively and promote the intercultural aspect of a mixed class in order to combat the negative preconception.

In the context of internationalization of universities, the role of international students in a university is emphasized: Their presence fosters local students' appreciation and respect of other cultures and experiences. However, not only international students, but all students have cultures and experiences that can be shared with other students.

In this study, I have argued that we should not dichotomize students into international and local students, or Asian and non-Asian students. An Australian university has students with various cultures, which is a goldmine for intercultural exchange. In this era of globalization, it is essential for students to develop an ability to communicate with, and learn from, people from diverse linguistic and cultural backgrounds. A university has a responsibility for providing young people with conditions that enable them to undergo a process of personal transformation through such intercultural exchange. I believe that a Japanese language course, for example, can give students opportunities to learn from each other, and reflect on themselves, using the Japanese language as a lingua franca. 


\section{References}

[1] Armour, W. S. (2011) 'Learning Japanese by reading manga: The rise of soft power pedagogy', RELC Journal, 42(2), pp. 125-140

[2] Berry, J. W., Poortinga Y. H., Segall M. H. and Dasen P. R. (2002) Cross-Cultural Psychology: Research and Applications, Cambridge: Cambridge University Press

[3] Berry, J. W. (2005) 'Acculturation: Living successfully in two cultures', International Journal of Intercultural Relations, 29(6), pp. 697-712

[4] Burns, R. (1991) 'Study and stress among first year overseas students in an Australian university', Higher Education Research and Development, 10(1), pp. 61-77

[5] Campbell, J. and Li, M. (2008) 'Asian students' voices: An empirical study of Asian students' learning experiences at a New Zealand university', Journal of studies in international education, 12(4), pp. 375-396

[6] Garrett, P. (2011) 'More opportunities to study Asian language', Media Release, Minister's Media Centre, Canberra, 28 Sept., 2011

http:ministers.deewr.gov.au/garrett/more-

opportunities-

study-asian-languages (Access date: 10 Oct., 2011)

[7] Gobel, K. and Helmke, A. (2010) 'Intercultural learning in English as foreign language instruction: The importance of teachers' intercultural experience and the usefulness of precise instructional directives', Teaching and Teacher Education, 26(8), pp. 1571-1582

[8] de Kretser, A. and Spence-Brown, R. (2010) The Current State of Japanese Language Education in Australian Schools. Melbourne: Education Services Australia

[9] Lane, B. (2010) 'Asian languages losing their allure', The Australian, 9 Jun., 2010

http://www.theaustralian.com.au/higher-education/asianlanguages-losing-their-allure/story-e6frgcjx-

1225877157372 (Access date: 12 Nov., 2011)

[10] Matsumoto, M. (2009) 'Persistence in Japanese language study and learners' cultural/linguistic backgrounds' Australian Review of Applied Linguistics, 32 (2), pp. 10.1-10.17

[11] McLaren, A. (2011) Asian languages enrolments in Australian higher education 2008-9, Melbourne: Asian Studies Association of Australia

[12] Northwood, B. and Thomson, C. K. (2010) 'Why stop studying Japanese? A case in Australia'. In A. M. Stoke (Ed.), JALT2009 Conference Proceedings. JALT, pp. 820832 ,

[13] Ramburuth, P. (2001) 'Learning diversity in higher education: A comparative study of Asian international and Australian students', Higher education, 42(3), pp. 333-333. [14] Ryan, J. and Viete, R. (2009) 'Respectful interactions: learning with international students in the Englishspeaking academy, Teaching in Higher Education, 14(3), pp. 303-314

[15] Sawir, E. (2005) 'Language difficulties of international students in Australia: The effects of prior learning experience', International Education Journal, 6(5), pp. 567-580

[16] Scarino, A. (2009) 'Assessing intercultural capability in learning languages: Some issues and considerations', Language Teaching, 42(1), pp. 67-80
[17] Soosay, C. (2009) 'International and domestic students' perspectives on teaching and learning', Journal of International Education in Business, 2(1), pp. 20-32

[18] Thomson, C. K. (2010) 'Understanding Australian learners of Japanese', オーストラリア研究紀要 (Australian research journal), 36, pp. 157-170

[19] White, H. (2011) 'Minding our languages', The Sydney Morning Herald, 8 Nov., 2011.

http://www.smh.com.au/opinion/minding-our-languages20111107-1n3pu.html on (Access date: 20 Nov., 2011) 